\title{
U.S. beef industry faces new policies and testing for mad cow disease
}

\author{
Kate O’Neill \\ $\nabla$
}

The years 2003 and 2005 were pivotal for the North American cattle industry. In May 2003, Canada announced its first case of bovine spongiform encephalopathy (BSE), also known as mad cow disease. This was the first time North America's indigenous cattle had been confirmed to have BSE. Seven months later in December, the U.S. Department of Agriculture (USDA) announced that a dairy cow in Washington state (born in Canada and brought into the United States in 2001, at about 4 years old) had also tested positive for BSE. Then, in June 2005 USDA confirmed another U.S. case, this time "home-grown," a 12-year-old cow from a herd in Texas. These events have resulted in vigorous debates over testing cattle for BSE in the United States, and several important new USDA regulations. The results of the United State's expanded cattle-testing program will be watched closely in light of differing risk assessments about the prevalence of BSE in the United States. Increased testing could also have serious impacts on both domestic consumption and export markets for U.S. beef. Even as USDA continues to implement and refine new testing and other regulations, challenges from other countries and watchdog groups may result in more rigorous and transparent testing procedures. Other groups, including the beef industry, oppose more rigorous testing as causing unnecessary alarm.

While bovine spongiform encephacow disease, is prevalent in Europe, so far there have only been two confirmed

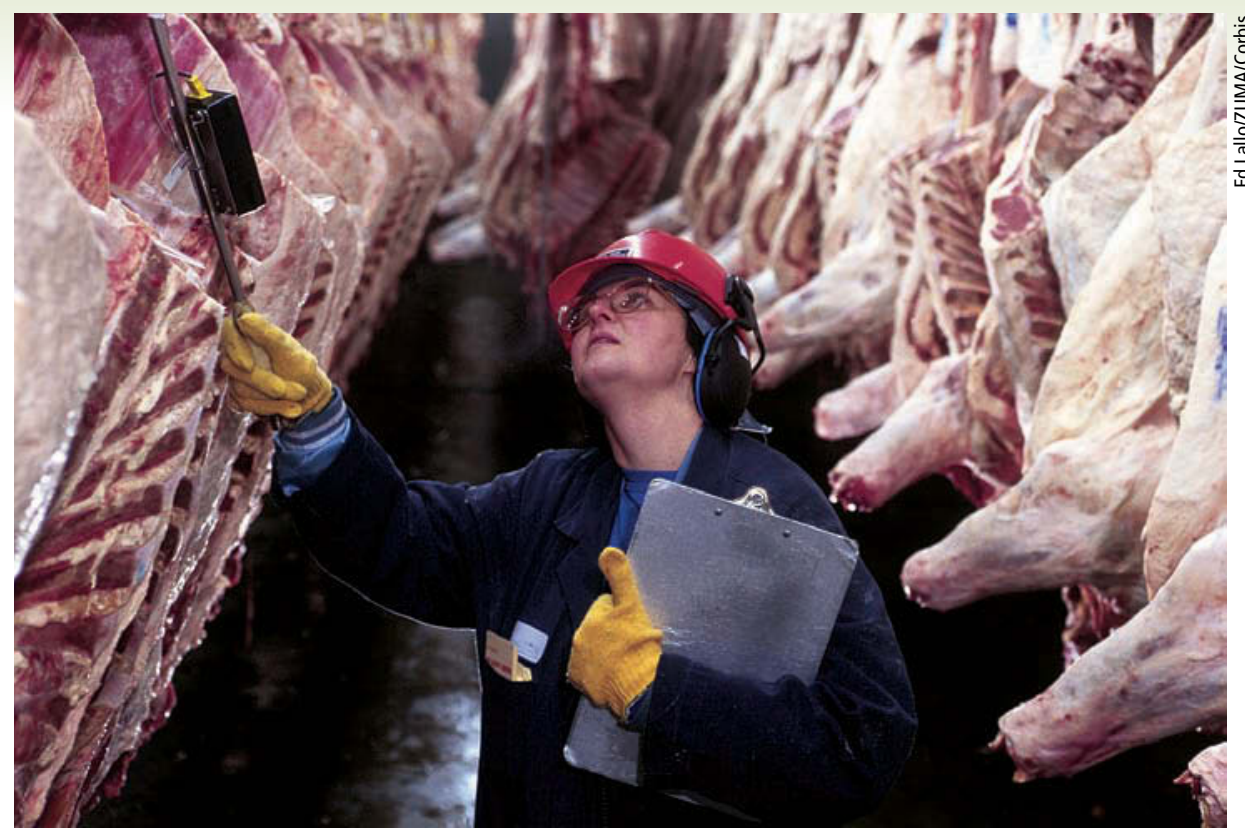

Two cases of bovine spongiform encephalopathy (BSE) have been confirmed in the United States since 2003, with broad implications for the U.S. meat industry. Above, a meat inspector looks over cattle carcasses in a Kansas slaughterhouse.

cases in the United States. A dairy cow from Washington state tested positive for BSE in December 2003, and another from Texas in June 2005. Two cases amid 95 million U.S. cattle might appear insignificant. Certainly, two cases have few implications for public health.

Nor were these cases exactly a surprise. Three major scientific studies on the risk of BSE in the United States had argued that a few cases would not be unexpected (European Commission on Food Safety 2000; HCRA 2001; GAO 2002). Indeed, subsequent investigations discovered that the first infected cow was born in Canada, and most likely was infected there, technically allowing the United States to maintain its official BSE-free status, according to the World Organization for Animal Health Standards.

Similarly, the domestic consumer reaction has been muted. While consumer awareness of the 2003 Washington BSE case was high, $65 \%$ believed the nation's beef supply was safe and only $1 \%$ claimed to have given up beef for good, according to a January 2004 survey by the Rutgers University Food Policy Institute (Hallman et al. 2004).
Furthermore, most consumers gave high marks to government officials for their handling of the case.

However, the international response was different. Fifty-three countries closed their borders to U.S. beef within days of Dec. 23, 2003, affecting the entire U.S. export market and accounting for $10 \%$ of U.S. production (Food Chemical News [FCN], Jan. 5, 2004). This reaction mirrors the experience of other countries such as Canada, Germany and Spain immediately after they announced minor outbreaks of BSE.

As a result of the North American BSE cases, and in response to demands from trading partners, the United States began reforming its BSE policy. This entailed tightening internal controls on slaughtering practices, tracking and BSE testing (for chronology see sidebar, page 204). These changes will be discussed in depth below.

California, as the fourth-largest cattle-producing (dairy and beef) state, will bear a strong burden of adjustment to new practices and policies laid down by the U.S. Department of Agriculture (USDA). Moreover, some California constituencies, especially consumer 
Sincer ince the first reports of BSE in the United Kingdom in 1986, the United States has responded with import bans, testing programs, ruminant feed rules (to prevent the spread of disease in animals), slaughterhouse regulations (to protect the human food chain) and animal tracking proposals.

Regulations now in place are subject to change when final rules are set, and the success of implementation varies. The U.S. Department of Agriculture (USDA) Food Safety and Inspection Service (FSIS) recently reported close to 1,000 violations of new slaughterhouse rules. Although policy-makers have proposed tracking systems, none has yet been implemented. (Consequently, 11 cows of the birth herd from the Dec. 23, 2003, BSE case were never located.)

1988: Rising BSE cases in United Kingdom prompt USDA to set up an interagency working group.

1989: United States bans imports of live cattle, cattle feed and beef products from the United Kingdom (or any country where BSE is found).

1990: U.S. BSE testing begins; 40 cattle brains tested.

1996: First cases of vCJD officially recorded in the United Kingdom.

1997: United States bans imports of live cattle, cattle feed and beef products from all of Europe.

United States bans feeding of "most mammalian proteins" to ruminants. Exceptions are mammalian blood and blood products and feed destined for nonruminants, such as poultry, which could later be rendered for cattle feed.

2002: U.S. cattle-testing program for BSE expands; 19,990 cattle brains tested.

May 2003: First Canadian BSE case confirmed.

December 2003: First U.S. BSE case confirmed.

January 2004: New USDA/Food and Drug Administration (FDA) regulations announced. Because feed restrictions proposed in November 2002 by FDA were stalled in the rulemaking process, FDA publishes an "interim final rule," which is subject to change when final rules are established.

USDA bans downer cattle and specified risk materials from entering the human food chain (see glossary, page 206). Ban extends to mechanically separated beef using AMR methods and air injection stunning. Both of these technologies can lead to specified risk materials entering the human food chain (FCN, Jan. 5, 2004).

March 2004: USDA begins testing as many cows as possible from the highestrisk population: downers and cows older than 30 months with BSE symptoms, such as emaciation or unusual behavior (agitation or kicking). USDA vastly increases annual testing rates, with the majority of the program voluntary; testing is mandatory for cattle condemned

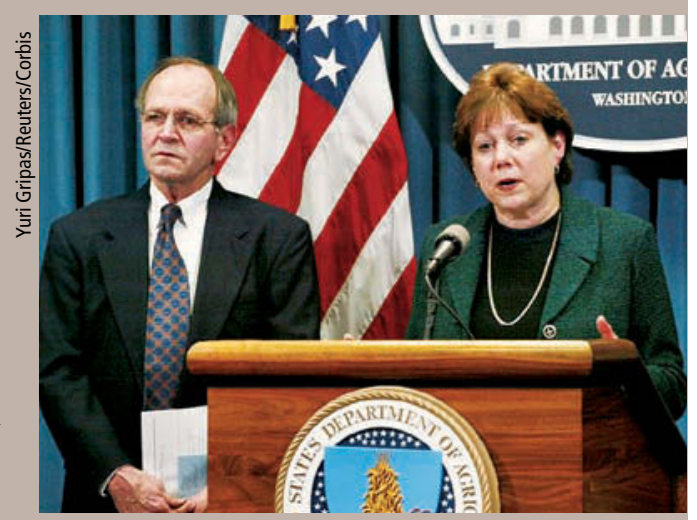

On Dec. 23, 2003, then-U.S. Agriculture Secretary Ann Veneman (right) and USDA Undersecretary Bill Hawks briefed the media regarding the slaughter of an animal with BSE from rural Washington state.

prior to slaughter. USDA also implements the "test and hold" policy, which prohibits downers from being processed until tests are confirmed negative. USDA introduces rapid screening tests used widely in the rest of the world, with inconclusive results subject to a slower immunohistochemistry (IHC) test (see page 206).

June 2005: Second confirmed U.S. BSE case (first U.S.-born case). Testing problems come to light because it had taken USDA 7 months to reach a conclusive result, and this came only after USDA was ordered to perform the Western blot test. In the wake of criticism, USDA added a confirmatory Western blot to the second round of testing, in addition to the IHC tests (New York Times, June 25, 2005).

September 2005: Between June 1, 2004, and Sept. 18, 2005, just over 470,000 tests are completed, with one positive result. In addition to high-risk cattle, USDA plans to test a random sample of 20,000 healthy cattle over 30 months of age. groups and the organic agriculture movement, are calling for the state to take action above and beyond the federal mandate. In response, state senators Jackie Speier (D-S.F./San Mateo) and Mike Machado (D-Linden) introduced a bill that sought to test all cattle slaughtered in California for BSE. While this bill died in committee, as of July 2005 the California Legislature was considering three separate measures dealing with testing on farms, country of origin labeling and beef recall disclosure, respectively. However, the history of strong centralization in policymaking in this arena suggests that the USDA is likely to oppose these efforts.

\section{British epidemic}

BSE was first reported in the United Kingdom in 1986 and soon became epidemic among British cattle. It is largely accepted that these cattle were infected through being fed meat-and-bone meal (MBM) from BSE-infected sheep or cattle. BSE is one form of transmissible spongiform encephalopathies (TSE), diseases that destroy brain tissue, and cause disorientation, loss of motor and cognitive skills, comas and, quite rapidly, death. The human form of TSE is called Creutzfeldt-Jakob disease. TSEs are caused by prions (see sidebar, page 206) and currently there are no vaccines, cures or officially sanctioned live-animal tests, with the exception of third eyelid testing in sheep. Progress is, however, being made on developing live-animal tests (London Observer, June 6, 2004).

What was most disturbing about the British BSE epidemic was that the infectious prion causing the illness in cattle was able to jump species and soon infected the human population, an unprecedented event. In the early 1990s, the deaths of young people in the United Kingdom from a mysterious brain-wasting disease became a media scandal, and scientific evidence began to point definitively to a link between BSE and a new form of the human TSE, known as variant CJD (vCJD). However, it was not until 1996 that the British government officially acknowledged this link. This crisis led to the slaughter of millions of cattle, long-standing trade embargoes, and severe loss of public confidence in the governance of food safety in the United Kingdom and 


\section{Glossary of terms}

Bovine spongiform encephalopathy (BSE): One of several diseases characterized by fatal degeneration of brain and central nervous system. The infective agents are misfolded prions found in brain and other tissues. Prions can transmit the disease from the diseased animal to another host under certain conditions. BSE primarily affects cattle and develops when cattle eat feed contaminated with the infectious agent.

\section{Variant Creutzfeldt-Jakob disease (vCJD): A fatal neuro- degenerative prion disease in humans. Nearly 200 humans worldwide who ate beef or beef products containing the BSE agent have contracted this disease, first identified in 1996.}

\section{Immunohistochemistry (IHC) test:}

One of two confirmatory tests used when rapid-screening tests are inconclusive. IHC involves microscopic examination of an intact portion of the brain, the obex, to see if there are lesions (holes or a spongy appearance) characteristic of BSE, and use of a staining process with antibodies that detect the abnormal prion protein. It takes 4 to 7 days to run.

Prion: "Proteinaceous infectious particle," as defined by UC San Francisco neurologist Stanley Prusiner, who won the Nobel Prize for his discovery of this new biological principle of infection. All known prions are misfolded versions of normal cellular proteins. Prions accumulate in cells by influencing the normal, cellular prion protein to assume the disease-associated form. Misfolded prions resist digestion by enzymes that regularly "recycle" proteins. Aggregates of the misfolded protein build up and are associated with TSE infectivity and neurodegenerative diseases in both animals and humans.
Prion protein: The normal form of a protein found mainly in the body's nerve cells. Its metabolic pathway and physiological function are currently unknown. This protein is sensitive to digestion by enzymes.

Specified risk materials: In 2004, ruminant tissues deemed "specific risk materials" were banned from the human food chain in the United States (Federal Register 2004). Defined as skull, brain, trigeminal ganglia, eyes, vertebral column, spinal cord and dorsal root ganglia of cattle 30 months of age or older, as well as the small intestines and tonsils of all cattle.

Transmissible spongiform encephalopathy (TSE): All diseases associated with the presence of prions in central nervous system tissue. Prions from TSE-affected brain tissue are believed to transmit the neurodegenerative disease state from the affected animal to another host.

Western blot: One of two confirmatory tests used when rapid screening tests are inconclusive. Researchers use a large portion of obex brain tissue; the abnormal prion protein in brain material is concentrated by ultracentrifugation, and the sample is exposed to the enzyme protease to destroy any normal prion proteins that may be present. The remaining sample is then run through a gel to separate the abnormal prion protein components by molecular weight. After the transfer of the proteins to a membrane, proteins are stained using antibodies that can identify a specific banding pattern associated with prion diseases, including BSE. Scientists make diagnoses by recognizing three distinctive bands identified as a result of a reaction with the antiprion protein antibody.

Sources: Advancing Prion Science: Guidance for the National Prion Research Program (2004), National Academy of Sciences; USDA-APHIS, www.aphis.usda.gov/ Ipa/pubs/fsheet_faq_notice/faq_BSE_confirmtests.pdf. federal agencies when firms - from feed mills to slaughterhouses - failed official inspections.

Despite the Harvard study's support for BSE being a "foreign" threat, consumer activist groups in the United States have continually challenged this perception. They argue that the national policy establishment ignored potential internal sources of infection as well as the probability that infectious prions were already circulating within the U.S. cattle system and potentially being transmitted to humans (Rampton and Stauber 1997). Prominent consumer groups tracking BSE in the United States include the National Campaign for Sustainable Agriculture, the Consumer Federation of America, Consumers Union, Public Citizen, and the Institute for Agriculture and Trade Policy.

Following the announcement of the Canadian BSE case in May 2003, U.S. officials started reassessing the country's vulnerability. In response to assessments by international experts and under pressure from Japan, a major importer of U.S. beef, agency officials began rethinking how the United States should approach BSE as a policy problem (Reuters, July 7 and 29, 2003). This process was accelerated by the Washington state BSE case that was reported on Dec. 23, 2003. On Dec. 30, 2003, USDA Secretary Ann Veneman announced new measures to control BSE, followed by the FDA on Jan. 26. The USDA measures included: banning all nonambulatory cattle (so-called downer cows) from the slaughter process; removing specified risk materials (SRMs), such as brain and spinal cord tissue, from meat entering the human food supply; and beginning to construct an adequate national system of animal identification (FCN, Jan. 4, 2004).

Cattle are classified as "downers" when they cannot walk, for any reason, from a broken leg to neurological damage. Europeans have long banned such cattle from entering the food chain, as they pose the highest risk of having BSE. In terms of SRMs entering the human food chain, two long-entrenched practices - air-gun stunning and advanced meat recovery (AMR, a technique used to take every possible scrap 
of meat from a carcass) - carry a risk of blasting SRMs into meat intended for human (or pet) consumption. Air injection stunning is banned and AMR is restricted under the new USDA regulations. Finally, cattle-tracking is important because, in the event of a positive test for BSE, authorities can trace the infected animal's movement from farm to farm, and to its birth herd and progeny.

The FDA also proposed - but later scrapped - feed rules that would have excluded blood and blood products, poultry litter and "plate waste" from restaurants in cattle feed (FCN, July 12, 2004). As of this writing, new feed rules are expected but have not been released.

Implementation of the new slaughterhouse regulations has been slow. According to recent data released after a Freedom of Information Act request from Public Citizen, the U.S. Food Safety and Inspection Service is still finding hundreds of violations of the new SRM rules at meat plants (FCN, Aug. 15, 2005).

These new measures imposed heavy costs on the beef industry. The industry itself estimated potential costs as somewhere between $\$ 183$ million and \$225 million (FCN, Feb. 16, 2004). However, they have satisfied neither consumer groups nor some important trading partners, notably Japan and other East Asian countries. As of August 2005, import bans or restrictions on U.S. beef and/or live animals and beef products remain in place in 59 countries (APHIS 2005).

\section{Testing policies and programs}

There are two main types of postmortem tests for BSE. Rapid tests can provide an almost immediate diagnosis, enabling testing of large numbers of cattle without delaying their use in food supplies. In the European Union, when a rapid test comes back with a positive or inconclusive ("presumptive positive") result, slower confirmatory tests are used, including the IHC and Western blot tests; the latter can be used on poorer quality tissue samples (see sidebar, page 206).

Prior to December 2003, USDA tested the brain tissue of slaughtered cattle for BSE solely via histological

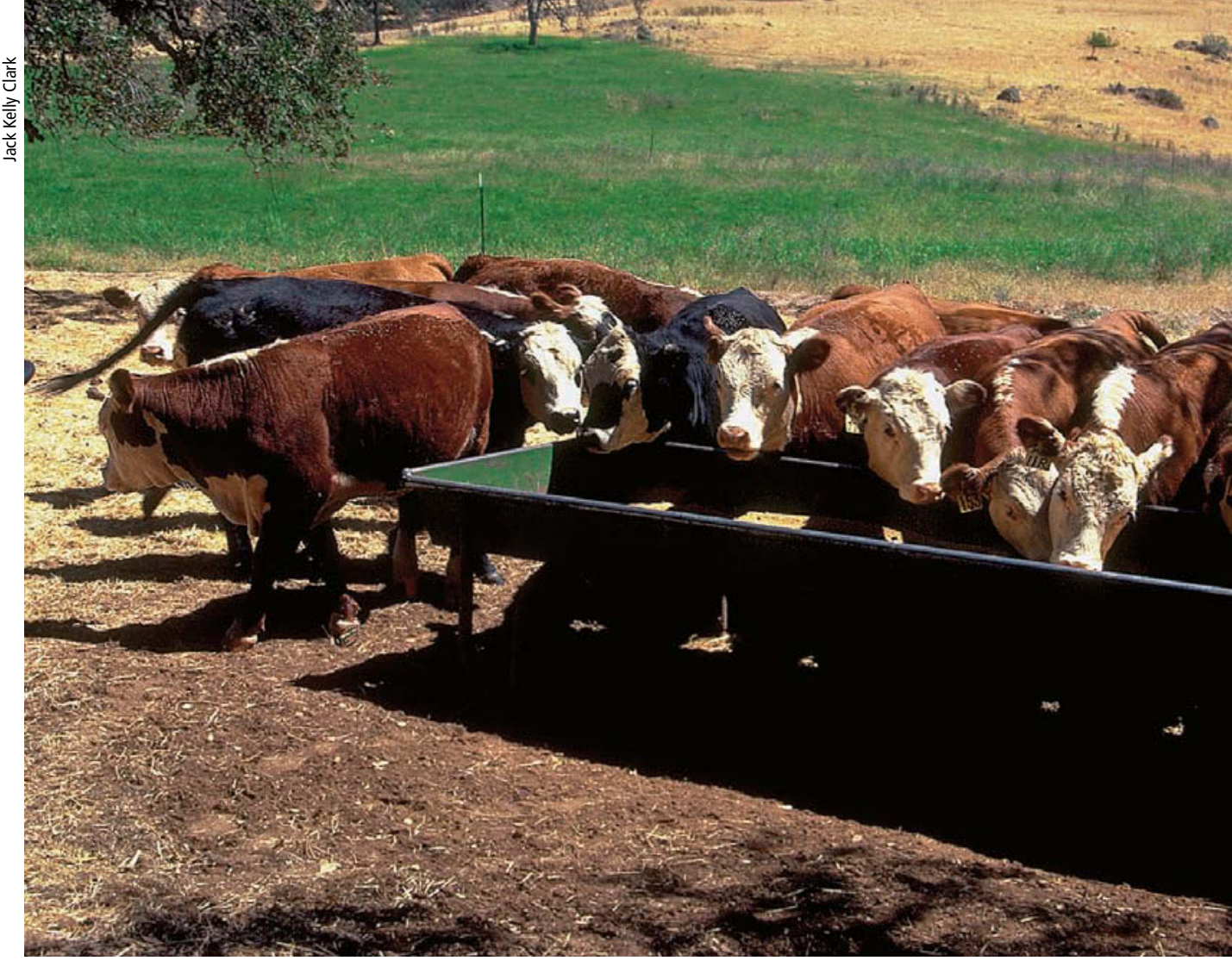

The scientific consensus is that BSE is transmitted via contaminated cattle feed. Above, livestock feed at the UC Sierra Foothill Research and Extension Center.

examination and immunochemistry. Known as the "gold standard" of BSE testing (APHIS 2004a), IHC tests are labor-intensive and the entire process takes up to 2 weeks, as opposed to the 24 hours it takes for results from the rapid tests approved by the European Union. The USDA Animal and Plant Health Inspection Service (APHIS) began testing cattle brains for BSE in 1990, testing 5,272 in fiscal year (FY) 2001 and 19,990 in FY 2002. In FY 2003, APHIS tested 20,543 brains, following a targeted testing strategy of focusing on the "higher risk" population: "adult cattle with central nervous system clinical signs and nonambulatory [downer] cattle" (APHIS 2004a). In contrast, the European Union's rapid tests allowed them to assess 18 million cattle in 2002.

By 2003, the issue of cattle testing in the United States had already become a focal point of controversy (Tyshenko 2004). In light of E.U. studies attesting to the accuracy of rapid testing, it is unclear why the United States had not shifted to rapid testing before 2003 (Moynagh and Schimmel 1999). Consumer activists claimed that the APHIS was testing far too few cattle, and hinted, more darkly, that rapid tests were not used because they allowed more testing, increasing the likelihood that more cases might be found (Nelson 2001). Others have claimed that the rapid tests generate a higher number of false positives, which would then give rise to unnecessary alarm.

However, this is not an accurate perception (Moynagh et al. 1999). It is true that rapid tests for BSE are set to a high level of sensitivity, which means they readily pick up anomalies that may or may not be BSE. In countries that use these rapid tests, all such inconclusive results are then subject to further rounds of testing to provide the final confirmation of infection. Another factor to consider is that the cost of rapid tests is not insignificant: around \$10 to \$20 per cow. Although the federal government allocated an additional $\$ 47$ million dollars to BSE-related activities in the FY 2005 budget, including \$17 million for testing, it is possible that at least some of the additional costs are likely to be passed on to consumers.

Critical questions facing the U.S. policy establishment include which tests to use, how many cattle to test, which cows to test (downer cows, and/or all cows above a benchmark age), and whether to decentralize testing sites, and in particular, whether or not to allow testing on farms. Age is important because with two exceptions (in 21- and 
23-month-old cows tested in Japan), BSE tests have never detected BSE in cattle under 24 months old. The European Union uses 30 months as its benchmark age above which all cattle destined for consumption must be tested at slaughter. Advocates of on-farm testing argue that currently, farmers may destroy and bury downer cattle without reporting their existence, thus potentially masking a wider outbreak.

In January 2004, USDA announced a 10-fold increase in cattle testing, to 221,000 animals annually, including 20,000 tests of healthy, aged cattle. Most of the surveillance program is voluntary. Goals have been established for testing 300,000 or more animals annually. This sample size is designed to

\section{California will bear a strong burden of adjustment to new BSE practices and policies laid down by the U.S. Department of Agriculture.}

allow for the discovery of BSE even if national prevalence is only one in 10 million adult cattle. To do this, USDA has licensed five rapid tests, four of which are produced by U.S.-based private laboratories, several of which are based in California ( $F C N$, March $22,2004)$. All these tests are already in use in the European Union, Japan and Canada. In addition, seven state laboratories, including the California Animal Health and Food Safety Laboratory System at UC Davis, will be allowed to carry out testing, with another five to be added over the next year. Protocols issued at this time stipulated a two-step process, with inconclusive results from the rapid screening test to be followed up with the IHC test to confirm results at the USDA's National Veterinary Services Laboratory in Ames, Iowa (APHIS 2004a).

Then, in June 2005, it transpired that the second BSE-infected cow had only been confirmed as positive 7 months after its first, inconclusive rapid test. Flaws in the testing process, including two IHC tests with conflicting results, led the USDA's Office of the Inspector General to request that the sample be tested using the Western blot test - at that time, not an authorized test (FCN,
July 4, 2005). Once this story came out, USDA testing procedures and protocols were heavily criticized: Michael Hansen, senior research associate of Consumers Union, referred to USDA's "triple firewall" defense against BSE as "more of a white picket fence" (New York Times, June 25, 2005). In response, USDA added the Western blot test to its testing protocols, and the department has vowed to correct procedural errors made in this case, including a failure to keep records, and mixing up parts from different cattle. Inconclusive results from rapid tests will now be subject to both IHC and Western blot tests.

The decisions that the United States makes about cattle testing will signal to both its trading partners and internal critics how it intends to proceed in addressing BSE over the longer term. The stakes are high in the development of new testing standards. First, it is likely that the authorities will continue to find more cases. USDA chief veterinarian Ron DeHaven recognized as much in a March 15, 2004, briefing, admitting that "there is a chance that we could find more positive cattle," before assuring the audience that prevalence is low and the threat to public health minimal (FCN, March 29, 2004).

Ultimately, it is uncertain how many BSE-positive cattle will be found, nor is it certain how this could affect consumer confidence. However, it is clear that major export partners have a very low risk-acceptance threshold. Japan initially demanded that the United States test all cattle slaughtered for export to its markets, and Mexico is unwilling to accept imports of beef products from the United States that may contain any risk materials (FCN, April 26 and May 10, 2004). Further, the existence of new cases could disprove dominant official risk-assessments of the extent of BSE within the United States. USDA and FDA have strongly rejected the possibility, proposed by an international expert advisory committee in 2004, that BSE is now indigenous to North America and most likely circulating within both the United States and Canada (FCN, Feb. 9 and April 5, 2004; APHIS 2004b). These federal agencies are also deeply skeptical of possible indigenous sources of infection.

\section{Experiences of other countries}

The experiences of other countries that also initially found one or a few BSE cases are instructive. Germany's first seven indigenous cases, found in 2000, triggered a massive response from consumers and trading partners, and led to major reforms of German food safety policy. After fully implementing the European Union's BSE control regime, Germany started finding higher levels of the disease: 125 cases in 2001, 106 in 2002, 54 in 2003 and 65 in 2004 (OIE 2005a). Similarly, after finding two indigenous cases in 2000, Spain also found higher levels of BSE: 82 in 2001, 127 in 2002, 167 in 2003 and 137 in 2004 (OIE 2005a; Bird 2003). Japan found its first three cases in 2001, two in 2002, four in 2003 and five in 2004 (OIE 2005a).

In each of these cases, higher rates of testing led to more cases being found, albeit to differing extents and with differing results. Both Germany and Japan responded with fundamental reform of their policies to date. In Germany, consumer outrage led to a collapse in beef consumption, the resignation of prominent ministers, and a new ministry for Consumer Protection, Food and Agriculture (Imort 2001). Germany is now in full compliance with E.U. rules, which since 2001 have required testing of all symptomatic animals as well as animals older than 30 months sent for slaughter, and banned the feeding of mammalian proteins to all farm animals (SSC 2001). Spain also implemented E.U. policies, but beyond that, there were fewer institutional repercussions (European Commission 2002). Again, as in Germany, domestic beef sales collapsed (they were down by $50 \%$ soon after the initial outbreak), and farmers and bullfighters protested, demanding compensation (New York Times, Dec. 1, 2000). Japan, which also experienced a collapse in consumer trust in governance, until August 2005 required testing of all cattle sent for slaughter - the most precautionary reaction to date of any BSE-affected country (McCluskey et al. 2004). However, this is a far easier task than 


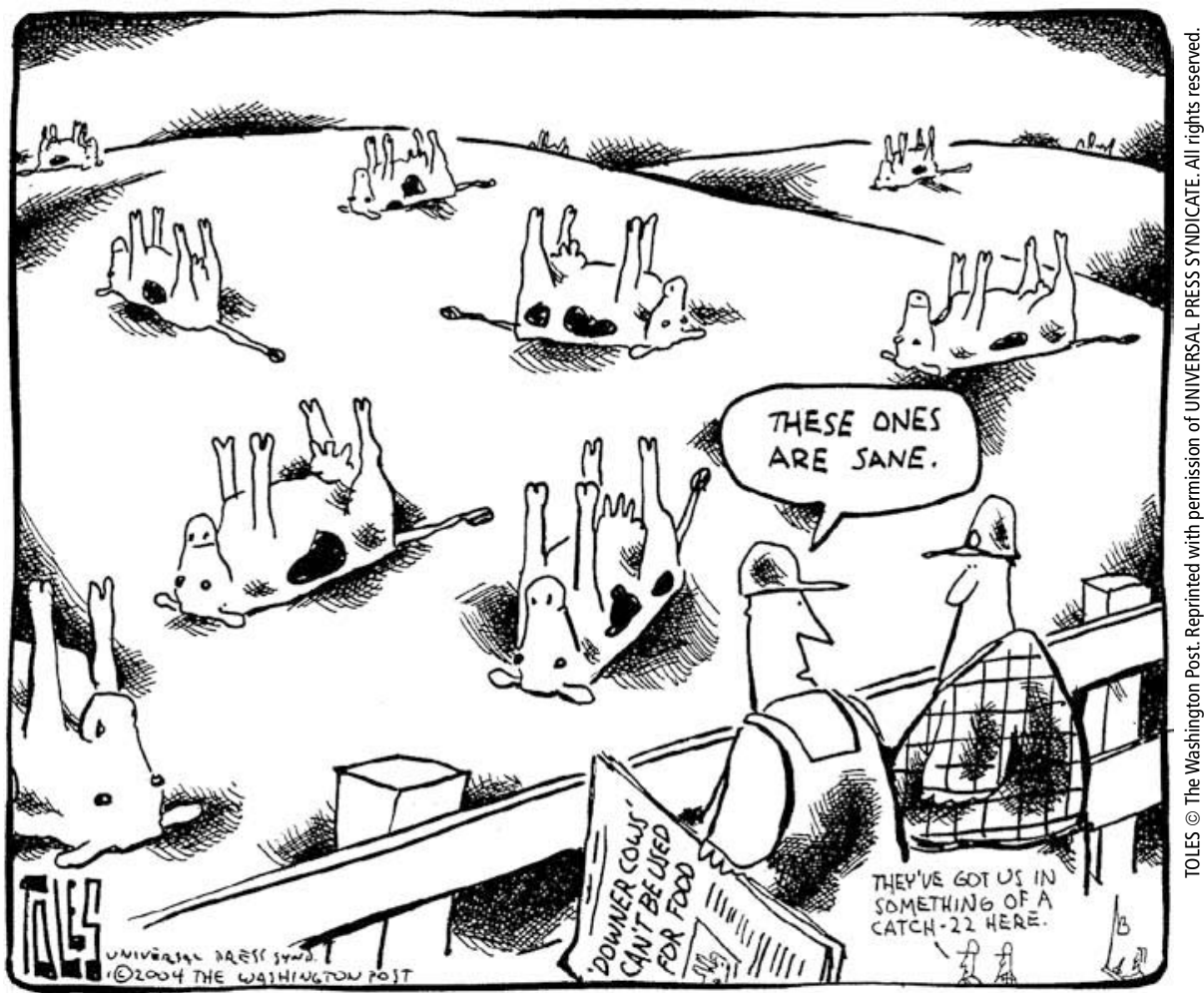

Political cartoonist TOLES of the Washington Post skewered mad cow disease on Jan. 1, 2004.

in the United States, as Japan typically slaughters only around 1.2 million head of cattle annually, roughly $3 \%$ of U.S production. (MAFF, 2002, table 2.8).

\section{BSE in the United States}

Unlike in Germany, Spain and Japan, U.S. consumer confidence in U.S. beef has remained stable in the wake of the two BSE cases. However, it is by no means certain this would still be true if tens or hundreds of new cases were found, and the United States could also face the long-term loss of beef export markets. Experts on all sides are now holding their breaths for the results of the expanded U.S. BSE testing, but there is little consensus on what USDA is likely to find (FCN, March 22, 2004).

First, it is widely accepted that spontaneous TSEs emerge in older animal and human populations at rates of 1 in 1 million (HCRA 2001). This alone suggests the expanded program will lead to more cases being found, depending on the age of the cattle cohort. Second, a great deal depends on the proportion of at-risk stock, especially nonambulatory downer cattle older than 24 months, present in the testing sample, as these cattle have markedly higher rates of BSE prevalence (Bird 2003). Third, some worry that USDA's assumption that all animals testing positive will come from this highrisk group may be flawed. Hansen of Consumers Union has pointed out that BSE can also be found in apparently healthy animals, and that by largely excluding this population, authorities could underestimate the true BSE prevalence ( $F C N$, March 22, 2004). Two authors of the Harvard study agreed with this assessment (Cohen and Gray 2004).

As important as the number of cases found over the next few years will be the trajectory of cases. It is impossible to tell whether the United States will mirror Germany (cases rising initially then falling significantly) or Spain (with new cases rising, then leveling off at over 100 per year). The latter scenario would likely be worse for consumer confidence than the former. Existing risk assessments vary in their predictions. The Harvard study (HCRA 2001) was highly optimistic about the ability of the existing U.S. system to dampen and eliminate BSE circulation. In contrast, the Geographical BSE Risk (GBR) study, which was commissioned by the European Union and published in 2000, was less optimistic. The GBR study concluded that if the United States had been exposed to cases originating from the United Kingdom before effective measures were put in place in the mid- to late 1990s, it is highly possible that by now these cases would have generated a number of second- or third-generation cases (SSC 2000).

The GBR study assessed the BSE risk of close to 60 countries, based on how well they could both prevent the disease's introduction across their borders (external challenge) and reduce its spread within their borders (internal stability) (SSC 2000). The study's assessments of Germany, Spain, the United States and Canada were all published in 2000, before any of these countries had reported BSE, and placed the North Americans and the Europeans into different categories of risk. As of 2000, the United States and Canada fit into GBR Level II (BSE unlikely but not excluded), while Spain and Germany fit into GBR Level III (BSE likely but not confirmed). On the face of it, this implies that Spain and Germany are far more vulnerable than the United States and Canada, therefore predicting that incidence of BSE in North America would be far lower over time.

However, the difference between these two groups was based on levels of external challenge: Germany and Spain, as European Union members, faced a far greater threat of BSE transmission from Britain, Portugal and other highly affected countries. In contrast, the picture looked very different in terms of internal stability: the United States, Canada and Germany were categorized as "neutrally stable" (neither amplifying nor reducing circulating BSE-infectivity over time), while Spain was categorized as "stable" (eliminating BSE over time). (Note that these assessments turned out to be at variance with actual outcomes over the following 4 years.) Each of these countries had moved from "highly unstable" in the early 1990s (before BSE-prevention measures had been put in place) to its 2000 position. If it turns out that the United States' external challenge was higher than initially assumed or has risen in recent years, the United States could turn out to look more like Germany or Spain in terms of BSE cases, with the ultimate outcome (numbers rising or falling over time) dependent on the effectiveness of and compliance with, internal measures put in place since May 2003. In fact, in August 2004, 
the SSC upgraded both countries to GBR Level III (BSE confirmed at a lower level: likely but not confirmed) (FCN, Aug. 30, 2004).

While these scenarios, based on the German and Spanish experiences, are hypothetical, they demonstrate that the underlying assumptions of expert risk assessments are vulnerable to challenge and reinterpretation as well as to error. Public debates between members of the international advisory panel commissioned by USDA to look into U.S. BSE policies and safeguards in January 2004, and authors of the Harvard study, indicate the gulf that can exist between groups of similarly qualified experts (FCN, Feb. 9, 2004). More generally, uncertainties remain about potential paths of BSE transmission - whether from other ruminants such as sheep or goats, or heredity - and about the institutional capacities of the U.S. policy establishment, in terms of closing regulatory loopholes in the face of resistance from the beef industry, or generating adequate enforcement of new requirements.

Certain stakeholder groups within the United States are concerned that USDA and FDA are dragging their feet over new controls, and that these measures may not be adequate, either in finding or preventing both existing and new BSE cases. USDA has, in response, been active in ensuring that it maintains centralized control over setting and implementing testing standards. For example in 2004, Creekstone Farms Premium Beef, a Kansas meatpacking firm that specializes in preparing beef for export to Japan, wanted to test all its cattle for BSE on-site. This bid to privatize testing standards was rapidly denied by USDA, which argued that there was no scientific justification for $100 \%$ testing (FCN, April 12, 2004), despite public and media support for the firm's actions (FCN, April 26, 2004). In California, state senators Machado and Speier sponsored legislation in March 2004 that would allow licensed slaughterers in California to voluntarily test all cattle carcasses for BSE. USDA and the beef industry both opposed this measure, and it died in committee. In addition to claiming that such measures are not justified, USDA claims that different standards across states would undermine competitiveness. Likewise, ranchers and beef producers are concerned about the costs of universal testing, and the fair implementation of the proposed California standard. At this stage, it looks as if USDA will maintain federal control over BSE testing, over and above the objections of several stakeholder groups. Nonetheless, California lawmakers remain active on this issue. As of July 25, three new bills stood before the California Legislature. One, SB 611, sponsored by Speier, deals with meat and poultry recall. A second, SB 905, sponsored by Machado, would allow independent testing by California ranchers. The third, $\mathrm{AB}$ 1058, sponsored by Assemblyman Paul Koretz (D-West Hollywood), would impose country-of-origin labeling for unprocessed beef.

\section{Consumers and trading partners}

Finally, scientific risk assessments do not tell us how results will be perceived or how consumers and trading partners will react. So far, U.S. consumers have been far more stoic about two cases of BSE than have U.S. trade partners, and there is some evidence that U.S. consumers demonstrate far more trust in government food safety regulation than do Europeans (Vogel 2003). ). Further, the economic impact on the U.S. beef sector has been far less than on its Canadian counterpart (O'Neill 2005).

The U.S. administration is currently engaged in actively wooing back former import partners, particularly Mexico and Japan. After months of negotiations, in October 2004 the United States and Japan announced they had reached a tentative framework agreement that would allow the beef trade between the two countries to resume within 12 months (New York Times, Oct. 24, 2004). Part of this deal involved Japan ending its policy of blanket testing for BSE, a move opposed by many Japanese consumers. But this deal remains vulnerable. Although the second U.S. BSE case did not change Japan's position, no timetable has yet been set for this ban to be lifted. New U.S. BSE policies, most particularly the strengthened feed and SRM ban, remain heavily contested by the beef industry, and, although the new testing program has been put in place, other protective mea-

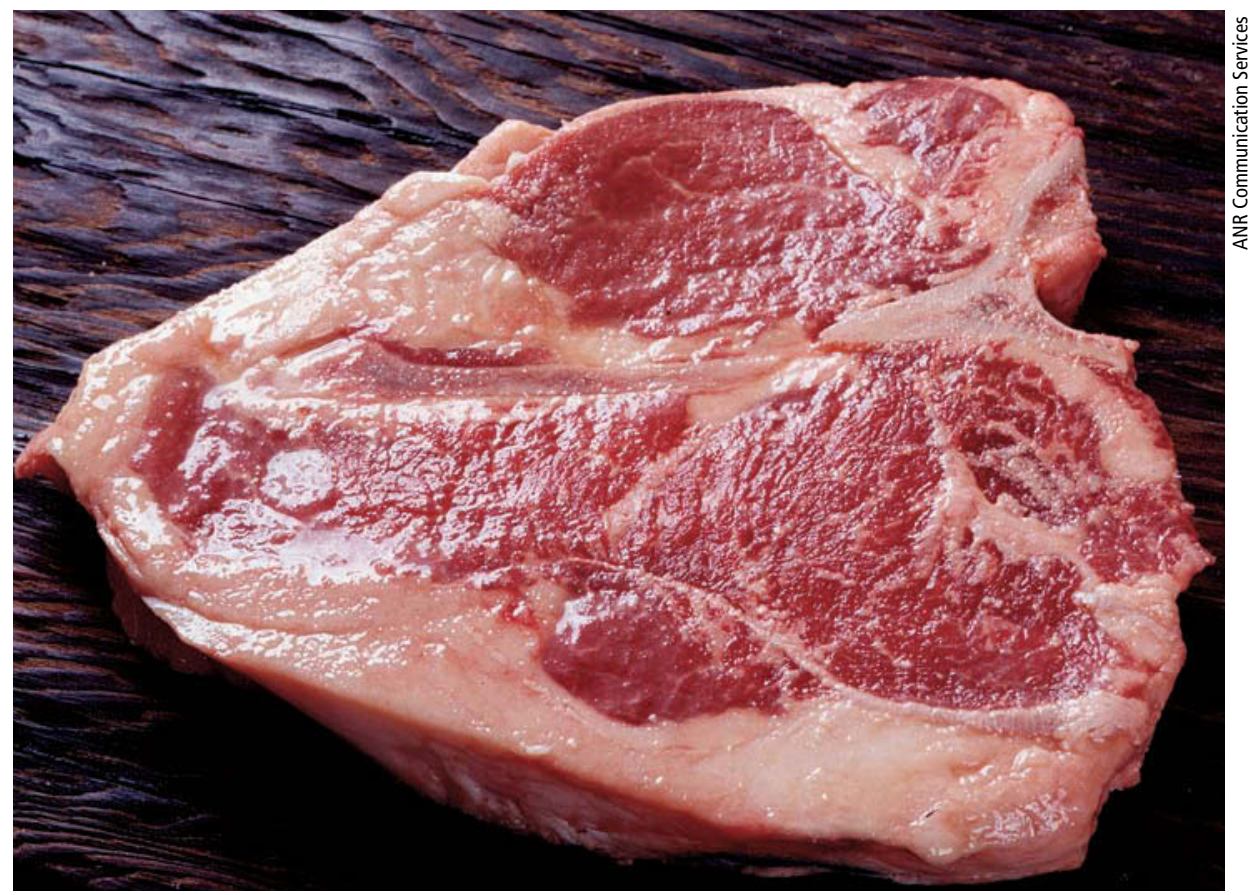

So far, the two confirmed U.S. BSE cases have not significantly shaken consumer confidence in the safety of homegrown beef. 
sures are yet to be fully implemented. If more BSE cases are found over the next few years, will actions taken to bolster consumer and foreign market confidence be in vain? Worse, is there a threshold over and above which consumer opinion will shift against U.S. beef?

U.S. regulatory authorities are facing some tough decisions about risk mitigation and communication, particularly in light of high economic stakes and strong opinions held by domestic and international constituencies. The decisions made about cattle testing in the wake of two BSE cases reflect both U.S. policy culture, and the policy-makers' desire to avoid the mistakes made by British counterparts in the 1980s. So far, USDA and FDA have done little to prepare the U.S. population for the possibility of longer-term economic impacts of finding new BSE cases, although, to their credit, they have done a good job of communicating their policy decisions and processes. Some, however, fear they have been too transparent over the issue of testing since the new program was implemented in June 2004, by disclosing every tentatively positive case prior to confirmatory tests. Other groups believe the USDA and FDA have not been transparent enough, for instance, in not disclosing their sampling procedures, including the geographic location of sampled cattle, their age and disease status. How USDA and FDA continue to walk this tightrope between transparency and reassurance over the next few years will be highly instructive, not only to the California agricultural community and elsewhere, but also to scholars of risk assessment and communication.

Although the incidence of BSE in the United States may seem like a minor problem at present, the responses of policy-makers and regulators provide useful case studies that put the magnifying glass to the workings of our regulatory, food production and distribution, and trade systems and relationships. We can use this BSE outbreak to examine the strengths and weaknesses in our responses to food safety issues, and glean important lessons for meeting future challenges that will undoubtedly come.
K. O'Neill is Associate Professor, Department of Environmental Science, Policy and Management, UC Berkeley.

\section{References}

[APHIS] Animal and Plant Health Inspection Service. 2004a. BSE Surveillance. www. aphis.usda.gov/lpa/issues/bse/bse-surveillance. html (accessed Aug. 13, 2005).

APHIS. 2004b. Response to 'Report on measures Relation to Bovine Spongiform Encephalopathy (BSE) in the United States,' March 2004. www.aphis.usda.gov/lpa/issues/ bse/bse_responsetorep.pdf (accessed Aug. 13, 2005).

APHIS. 2005. BSE Trade ban status as of 08/04/05. www.aphis.usda.gov/lpa/issues/bse/ trade/bse trade_ban_status.html (accessed Aug. 13, 2005)

Bird SM. 2003. European Union's rapid TSE testing in adult cattle and sheep: Implementation and results in 2001 and 2002. Stat Method Med Res 12:261-78.

Cohen J, Gray G. 2004. Comments on USDA BSE Surveillance Plan. Harvard Center for Risk Analysis, March 12. www.aphis.usda. gov/lpa/issues/bse/BSE_Harvard03-12-04.pdf (accessed Aug. 13, 2005).

European Commission. 2002. Final Report of a mission carried out in Spain from 14 to 18 October 2002 in order to evaluate the Implementation of certain EU measures aimed at the eradication, control and prevention of transmissible spongiform encephalopathies (TSE). Food and Veterinary Office. http://europa.eu.int/comm/food/fs/inspections/vi/reports/spain/vi_rep_spai_9123-2003_en.pdf (accessed Aug. 13, 2005).

European Commission on Food Safety. 2000. Report on the Assessment of the Geographical BSE-Risk (GBR) of the United States of America, July 2000. http://europa. eu.int/comm/food/fs/sc/ssc/outcome_en.html (accessed Aug. 13, 2005).

Federal Register. 2004. Prohibition of the Use of Specified Risk Materials for Human Food and Requirements for the Disposition of Non-Ambulatory Disabled Cattle. Fed Reg 69 (7):1861-74.

[GAO] General Accounting Office [Now General Accountability Office]. 2002. Mad Cow Disease: Improvements in the Animal Feed Ban and Other Areas would Strengthen U.S. Prevention Efforts. Report to Congressional Requesters (GAO-02-183)January 2002 www.gao.gov/new.items/d02183.pdf (accessed Aug. 13, 2005)

Hallman WK, Schilling BJ, Turvey CJ. 2004. Public Perceptions and Responses to Mad Cow Disease: A National Survey of Americans. Food Policy Institute, Rutgers University. www.foodpolicyinstitute.org/docs/summary/ madcowsum.pdf (accessed Aug. 13, 2005).

[HCRA] Harvard Center for Risk Analysis. 2001. Evaluation of the Potential for Bovine Spongiform Encephalopathy in the United States, Nov. 26. Harvard School of Public Health. www.hcra.harvard.edu/pdf/madcow. pdf (accessed Aug. 13, 2005).

Imort M. 2001. Reactions to BSE in Germany: Wurst case scenario or ecochondria?
First Annual Conference on Developments in Europe. Wilfrid Laurier Univ, Waterloo, Can.

International Expert Advisory Committee. 2004. Report on Measures Relating to BSE in the United States, Feb. 4. www.aphis.usda. gov/lpa/issues/bse/U.S._BSE_Report.pdf (accessed Nov. 20, 2004)

Jasanoff S. 1997. Civilization and madness: The great BSE scare of 1996. Public Understand Sci 6(3):221-32.

[MAFF] Ministry of Agriculture, Forestry and Fisheries. 2002. Statistics on Livestock Products Marketing, Statistics and Information Department. www.maff.go.jp/toukei/abstract/index.htm (accessed August 13, 2005)

McCluskey JJ, Grimsrud KM, Ouchi H, Wahl, TI. 2004. BSE in Japan: Consumers Perceptions and Willingness to Pay for Tested Beef. IMPACT Center Technical Working Paper 111, Washington State University. http:// impact.wsu.edu/report/tech_papers/pdf/04111.pdf (accessed June 17, 2004).

Moynagh J, Schimmel H. 1999. Tests for BSE evaluated. Nature 400:105.

Moynagh J, Schimmel H, Kramer GN. 1999. Preliminary Report: The evaluation of tests for the diagnosis of transmissible spongiform encephalopathy in bovines. European Commission, Directorate General XXIV, Consumer Policy and Consumer Protection.

Nelson JA. 2001. USDA mad cow strategy: Don't look, don't find. www.vegsource.com/articles/bse_usda.htm (accessed Aug. 13, 2005).

[OIE] International Organisation for Animal Health. 2005a. Number of Reported Cases of BSE worldwide (excluding U.K.) www.oie.int/eng/info/en_esbmonde.htm (accessed Aug. 13, 2005).

OIE. 2005b. Number of Cases of BSE Reported in the United Kingdom. www.oie. int/eng/info/en_esbru.htm (accessed Aug. 13, 2005).

O'Neill K. 2005. How two cows make a crisis: U.S.-Canada trade relations and mad cow disease. Am Rev Canadian Studies 35(2):295-319.

Powell D, Leiss W. 1997. Mad Cows and Mother's Milk: The Perils of Poor Risk Communication. Montreal, McGill-Queen's University Press. $308 \mathrm{pp}$.

Rampton S, Stauber J. 1997. Mad Cow U.S.A.: Could the Nightmare Happen Here? Monroe, ME: Common Courage Pr. 246 pp.

[SSC] Scientific Steering Committee of the European Food Safety Authority. 2000. Final Opinion of the SSC on the Geographical Risk of Bovine Spongiform Encephalopathy (GBR), adopted July 6. http://europa.eu.int/comm/ food/fs/sc/ssc/outcome_en.html (accessed Aug. 13, 2005)

SSC. 2001. Opinion on Requirements for Statistically Authoritative BSE/TSE Surveys, adopted 29/30 November, 2001. http://europa.eu.int/comm/food/fs/sc/ssc/outcome en.html (accessed Aug. 13, 2005).

Tyshenko M. 2004. BSE Risk in Canada, Part 2: Current Methods of Testing for Bovine Spongiform Encephalopathy (BSE). www. leiss.ca/bse/142 (accessed Aug. 13, 2005).

Vogel D. 2003. The Politics of Risk Regulation in Europe and the United States. Yearbook of European Environmental Law 3. 